\title{
An audit of dementia education and training in UK health and social care: a comparison with national benchmark standards
}

\author{
S. J. Smith ${ }^{1 *}$, S. Parveen ${ }^{2}$, C. Sass ${ }^{1}$, M. Drury², J. R. Oyebode ${ }^{2}$ and C. A. Surr ${ }^{1}$
}

\begin{abstract}
Background: Despite people living with dementia representing a significant proportion of health and social care users, until recently in the United Kingdom (UK) there were no prescribed standards for dementia education and training. This audit sought to review the extent and nature of dementia education and training offered to health and social care staff in the UK against the standards described in the 2015 Dementia Training Standards Framework, which describes the knowledge and skills required of the UK dementia workforce.

Methods: This audit presents national data concerning the design, delivery, target audience, length, level, content, format of training, number of staff trained and frequency of delivery within existing dementia training programmes offered to health and social care staff. The Dementia Training Standards Framework was used as a reference for respondents to describe the subjects and learning outcomes associated with their training.

Results: The findings are presented from 614 respondents offering 386 training packages, which indicated variations in the extent and quality of training. Many training packages addressed the subjects of 'person-centred care', 'communication', 'interaction and behaviour in dementia care', and 'dementia awareness'. Few training packages addressed subjects concerning 'pharmacological interventions in dementia care', 'leadership' and 'end of life care'. Fewer than $40 \%$ of The Dementia Training Standards Framework learning outcomes targeted to staff with regular contact with people with dementia or in leadership roles were covered by the reported packages. However, for training targeted at increasing dementia awareness more than $70 \%$ of the learning outcomes identified in The Dementia Training Standards Framework were addressed. Many training packages are not of sufficient duration to derive impact; although the majority employed delivery methods likely to be effective.

Conclusions: The development of new and existing training and education should take account of subjects that are currently underrepresented and ensure that training reflects the Training Standard Framework and evidence regarding best practice for delivery. Lessons regarding the limitations of training in the UK serve as a useful illustration of the challenge of implementing national dementia training standards; particularly for countries who are developing or have recently implemented national dementia strategies.
\end{abstract}

Keywords: Dementia, Education, Training, Audit, Workforce development

\footnotetext{
* Correspondence: s.j.smith@leedsbeckett.ac.uk

${ }^{1}$ Centre for Dementia Research, School of Health and Community Studies,

Leeds Beckett University, Leeds LS1 3HE, UK

Full list of author information is available at the end of the article
}

(c) The Author(s). 2019 Open Access This article is distributed under the terms of the Creative Commons Attribution 4.0 International License (http://creativecommons.org/licenses/by/4.0/), which permits unrestricted use, distribution, and reproduction in any medium, provided you give appropriate credit to the original author(s) and the source, provide a link to the Creative Commons license, and indicate if changes were made. The Creative Commons Public Domain Dedication waiver (http://creativecommons.org/publicdomain/zero/1.0/) applies to the data made available in this article, unless otherwise stated. 


\section{Introduction}

There are approximately 50 million people living with dementia worldwide [1], a number set to double every 20 years making dementia an international health priority [2]. Health and social care is a complex system that operates on many levels across different organisations. The health and social care workforce must be equipped with appropriate knowledge and skills to support the needs of people with dementia. This workforce includes any person who may come into contact with people living with dementia, or suspected dementia, in health and social care settings from the point of diagnosis to end of life. This may include healthcare professionals, allied healthcare professionals, pharmacists, general practitioners, clinical and non-clinical staff, porters, kitchen staff, and receptionists. People living with dementia represent a significant proportion of health and social care service users; up to $40 \%$ of patients in hospital [3] and $80 \%$ of people in residential care [4] live with dementia. Supporting people with dementia requires a range of skills since people living with dementia can experience behavioural changes influenced by cognitive impairment as well variations in general health and social circumstances [5]. Person-centred care has been widely adopted as a values-based approach to supporting people with dementia [6]. For this reason, person-centred dementia care is mandated in national [7] and international guidance [2]. High quality education and training are essential for delivering high quality dementia care, and ensuring appropriate caregiving strategies are used [8].

Despite the importance of education and training for the workforce, in the UK there is currently no mandated requirement for accredited training. Consequently, poor levels of knowledge about dementia in the workforce are common [9]. In response to the rising prevalence of dementia and associated pressure on health and social care services [3] the UK government has set targets to increase the number of staff in receipt of dementia training $[10,11]$. A national framework setting out the expectations regarding educational content and learning outcomes for England was published in October 2015 [12]. The Dementia Training Standards Framework, hereafter The Framework [13], outlines the essential subjects and learning outcomes that health and social care staff should accomplish to deliver an acceptable standard of dementia care. The Framework is divided into three tiers of Learning Outcomes (LOs). Tier 1 refers to training that all health and social care staff (as described above) should receive; LOs within this tier of training promote dementia awareness. For example porters, catering or kitchen staff should receive this training. Tier 2 sets out basic skills and knowledge relevant to any staff who have regular contact or provide direct care for people with dementia, such as registered nurses or care support staff. Tier 3 sets out advanced knowledge for leaders in the field of dementia care such as health and social care mangers, ward managers, dementia champions or dementia care trainers.

Whilst providing guidance for content, The Framework does not take account of the pedagogical considerations of training. The diversity of the dementia workforce presents unique challenges for providers. The majority of the workforce comprises unqualified care staff who are low paid, have low levels of literacy and numeracy, and who may have English as a second or additional language [14, 15]. Qualified staff in the workforce typically have degree level education, but accredited training generally lacks substantive dementia content [14]. A recent review sought to establish the common features of high quality educational provision for the dementia care workforce [16]. The review adopted Kirkpatrick's [17] model to conceptualise impact of training, whereby training with greater impact influences behaviour as well as knowledge. The findings indicated that education and training programmes with greatest impact were tailored to the recipient staff groups and relevant to their role and experience i.e. avoiding a one fits all approach. Better education and training included active participation (such as group discussions and activities) that underpinned practice-based learning with theory. Effective education and training lasted at least eight hours in total, with sessions of 90 min or more, and was delivered by an experienced facilitator. It also provided opportunities to support the application of learning in practice.

Although there have been policy initiatives designed to increase dementia education and training, no registration or accreditation for dementia training exist therefore there is no assurance regarding training quality. Having established The Framework for the ideal content of dementia training and identified effective approaches toward the delivery of education and training, it is now possible to better understand and describe education and training that is likely to be effective. The audit presented in this paper was funded by the National Institute for Health Research Policy Research Programme on behalf of Health Education England (HEE) within the What Works study with the aim of ascertaining the extent, nature and quality of education and training in dementia in the UK. The audit findings will thus enable recommendations regarding areas for development of education and training to better equip the workforce.

\section{Methods}

\section{Audit design}

Each respondent to the audit was required to report the number and nature of training packages they provided. For each training package reported the delivery method/ format of the training, target audience, length, content and level of training, number of staff trained and frequency 
of delivery was audited. In terms of content, the subject(s) and learning outcomes covered in the training or education (with reference to the Framework) provided by or within the organization was audited. Responses included open and closed force choice questions (see Additional file 1 for audit ${ }^{1}$ ). The audit was piloted with members of the project stakeholder monitoring group which included representation from the care home sector, primary care practitioners, hospital dementia leads, commissioners of training, and lay advisors with experience of supporting people with dementia.

\section{Setting and distribution}

Using an online web-based survey tool (Snap surveys; see https://www.snapsurveys.com/) an audit was distributed in England using databases of health and social care providers, training providers and training commissioners. We included commissioners as in the UK budgets and strategies for training provision for the health and social care workforce can sit with local commissioners of health and social care services, for example clinical commissioning groups or local authorities.

The distribution databases included extant resources held at the research sponsor University, national databases of professional networks (such as HEE distribution lists) and online lists of health and social care providers i.e. NHS Trust Research and Development (R\&D) offices, care home groups (www.carehome.co.uk accessed Nov 2015). In total 1621 invitation emails were sent from the University databases, the contacts were primarily from health and care organisations in the local region consisting private sectors and NHS (primary care practice, hospitals, trusts and clinical commissioning groups). The researchers also contacted 90 community pharmacies and local authorities. A further 226 individual care homes and care home groups were contacted from the directory held at carehome.co.uk. The direct emails were predominantly directed to lead nurse practitioners, directors or managers (clinical, finance, HR), education or training leads. Where participation was targeted, organizations were sent an email with an overview of the purpose of the research including a link to the online audit. Completion reminders included timed follow up e-mails. Each recipient received two reminders to complete the audit at two week intervals, after which no follow up was made.

The audit was also advertised via articles and adverts in journals read by the staff population and the use of

\footnotetext{
${ }^{1}$ Routing was employed in the online version based on participants' responses; respondents would not have been shown all questions. Questions regarding coverage of subjects and learning outcomes were repeated for each training package provided.
}

social media including Facebook and Twitter. The promotion of the audit included a direct link to the survey.

\section{Audit analysis}

The data was downloaded as one export from Snap Surveys into Microsoft Excel one month after the last reminders for completion were sent. Data cleansing included removing incomplete audit responses as described in the results section. Data was subsequently interrogated at the respondent and training package level. At the package level the degree to which training covered the subjects and learning outcomes identified in The Framework was analysed.

\section{Results}

\section{Overview of respondents}

In total 614 respondents commenced the audit. Of these 178 did not provide essential information and were excluded from analysis. Of the 436 remaining respondents (234 Care Providers, 129 Training providers and 47 Commissioners), 195 did not provide information about their training and were subsequently excluded. There were 241 respondents who provided data pertaining to at least one package (386 packages reported in total); an overview is provided in Table 1.

The majority of respondents were from care provider settings; hospital and residential care reported the highest number of packages. The fewest responses were received from domiciliary and primary care providers. In the training provider sector, most respondents came Universities. Overall fewest responses came from commissioners, although training provided from this sector reached large numbers of learners.

\section{Delivery methods}

Respondents provided detail regarding the delivery methods used for each package. Across the 386 packages the most commonly used method was face-to-face training or education in small groups (see Table 2). Few respondents reported using one-to-one approaches. Use of e-learning methods were reported by only $13 \%$ of respondents, although some respondents included online interactive tutorials under Other category, so this may be an underestimated. The Other category included use of online interactive tutorials, film and music, workshops and simulation. Respondents were able to assign more than one method to each package; some methods were used as stand-alone approaches and some concurrently.

\section{Recipients of training}

Detail concerning the recipients of training are reported in Table 2. Across the 386 packages around half of the packages were targeted to all staff groups, whilst 30\% were delivered to unqualified clinical or care staff (e.g. nursing assistant, support worker, residential care 
Table 1 Respondents, organisation type and number of education or training packages provided

\begin{tabular}{|c|c|c|c|}
\hline Provider Type & Organisation Type & $\begin{array}{l}\text { Number } \\
\text { Respondents }\end{array}$ & $\begin{array}{l}\text { Number of } \\
\text { Packages }\end{array}$ \\
\hline \multirow[t]{8}{*}{ Care Provider } & Hospital Care & 44 & 64 \\
\hline & Residential Care & 32 & 45 \\
\hline & Community Mental Health Trust, Mental Health Trust or Community Pharmacy & 23 & 31 \\
\hline & Charitable Care & 16 & 28 \\
\hline & Other Care Provider (E.g. Extra Care) & 14 & 19 \\
\hline & Primary Care & 9 & 12 \\
\hline & Domiciliary care & 5 & 9 \\
\hline & TOTAL CARE PROVIDER & 143 & 208 \\
\hline \multirow[t]{5}{*}{ Training Provider } & University & 40 & 74 \\
\hline & Other Training Provider & 18 & 30 \\
\hline & Private Training Company & 17 & 39 \\
\hline & Charitable Organisation & 12 & 20 \\
\hline & TOTAL TRAINING PROVIDER & 87 & 163 \\
\hline \multirow[t]{2}{*}{ Commissioning Group/Network } & COMMISSIONERS TOTAL & 11 & 15 \\
\hline & TOTAL & 241 & 386 \\
\hline
\end{tabular}

worker) and around $26 \%$ to qualified clinical or care staff (e.g. general practitioner, psychologist, nurse). Fewest packages were delivered to ancillary and clerical staff (e.g. porter, secretary, domestic staff). Respondents were able to identify that the training targeted more than one group. Respondents indicated that $12 \%$ of packages were delivered to "other" staff not listed in the audit options; these included people working with dementia in roles where they deliver training, volunteers and family members, members of public and schools.

\section{Length of training}

The audit captured how many hours' packages focused on dementia. Duration of the training was reported in hours for 299 out of 386 packages. The median length of the training was six hours (range 1-1800 h). Of the 299 packages, 102 (34\%) packages lasted more than $8 \mathrm{~h}$; previous research suggests training should be a minimum of eight hours [16]. Length of training in days was reported for 236 packages. The median length of the training was one day (range 1-1095), 48\% of packages (114) lasted for more than one day. The training with the longest duration represented a three year part-time MSc programme.

Details of how many times each package had been delivered were reported for 216 packages (median 8 times, range 1-300). Two hundred and thirty-nine packages reported the number of learners for each package (median 107 learners, range $7-15,000$ ), and 60 of the packages had been delivered to more than 500 learners. Higher numbers of learners were related to the package being delivered multiple times or to multiple organisations. One NHS trust delivered two programmes 100-150 times to 8000 learners in total. Overall 93 packages were delivered to multiple organisations. One training company delivered their package to 460 organisations and 15,000 learners across all types of health services, a fire service and shopping centres.

Respondents indicated that 352 of the packages covered at least one of the subjects identified in The

Table 2 Methods of delivery and recipients for 386 training packages reported

\begin{tabular}{llll}
\hline Method of Delivery & N (\%) packages & Recipients of Training & N (\%) packages \\
\hline Face to Face Small (less than 20) & $202(52 \%)$ & Unqualified Clinical Staff & $117(30 \%)$ \\
Face to face large (more than 20) & $81(21 \%)$ & Qualified Clinical Staff & $102(26 \%)$ \\
E learning & $51(13 \%)$ & Ancillary Staff & $29(8 \%)$ \\
One to One & $22(6 \%)$ & Unit/Ward managers & $66(17 \%)$ \\
Practice Based Learning & $62(16 \%)$ & Service managers & $57(15 \%)$ \\
Other & $20(5 \%)$ & All Staff & $189(49 \%)$ \\
& & Other & $48(12 \%)$ \\
\hline
\end{tabular}


Framework. The subjects that were most commonly addressed were 'person-centred care', 'communication', 'interaction $\mathcal{E}$ behaviour in dementia care', and 'dementia awareness' (see Table 3); over 300 packages addressed these subjects. Significantly fewer packages addressed 'pharmacological interventions in dementia care', 'leadership' and 'end of life care'.

For respondents who indicated that their package addressed a subject, the audit went on to require them to identify which LOs associated with the subject had been addressed by the training. A number of respondents indicated that they addressed a subject, but were unable to identify any LOs that the training addressed i.e. they overestimated the degree to which their training addressed the subject as described by The Framework (see Table 3). This was most apparent for the subject 'research and evidence based practice'; 176 respondents believed their packages addressed this subject but only 96 packages reported addressing at least one LO described in The Framework. Conversely, all but four respondents who identified addressing the subject 'assessment and diagnosis of dementia' addressed at least one $\mathrm{LO}$ from The framework.

In assessing the degree to which the content of the training met the needs of the dementia workforce, the proportion of LOs addressed for each subject area was interrogated. The mean number of LOs covered in each subject area was calculated. Packages focused on 'leadership in transforming dementia' care covered 89\% of the LOs described in the Framework- suggesting that although there were fewer packages addressing this subject, those that did provided education and training in accordance with The Framework. Similarly, packages addressing 'dementia awareness' delivered training largely aligned to the framework ( $81 \%$ of LOs covered). However, packages focused on 'research $\mathcal{E}$ evidence based practice in dementia care' only delivered $23 \%$ of the LOs described in The Framework. For 'pharmacological interventions in dementia care', 'equality diversity $\mathcal{E}$ inclusion in dementia care' and 'end of life dementia care' fewer than $50 \%$ of the LOs from The Framework were addressed.

Of the 386 packages, 137 (35\%) had an assessed component, whilst only 98 (25\%) were accredited. There were a range of accreditation types, from academic accreditation to vocational accreditation e.g. National Vocational Qualification (NVQ), and Continuing Professional Development (CPD). Some reported endorsement from the third sector such as the Alzheimer's Society.

The final consideration of the audit was establishing the level at which training was delivered. Of the 352 education and training packages delivered the mean proportion of LOs addressed was established from the total number of LOs described in each tier of the framework (Tier $1=73 \%$, Tier $2=36 \%$, Tier $3=39 \%$ ), see Fig. 1 . These findings indicated that whilst Tier 1 packages

Table 3 Overview of Packages; Subjects and Learning Outcomes (LOs)

\begin{tabular}{|c|c|c|c|c|c|c|}
\hline & $\begin{array}{l}\text { No. of packages } \\
\text { that address } \\
\text { subject }\end{array}$ & $\begin{array}{l}\text { No. of packages that } \\
\text { addressed at least } \\
\text { one subject level LO }\end{array}$ & $\begin{array}{l}\text { Diff. between } \\
\text { predicted and } \\
\text { actual coverage } \\
\text { of LOs }\end{array}$ & $\begin{array}{l}\text { Number of } \\
\text { LOs in Subject }\end{array}$ & $\begin{array}{l}\text { Av. Number of } \\
\text { LOs addressed }\end{array}$ & $\begin{array}{l}\% \text { of LOs } \\
\text { addressed }\end{array}$ \\
\hline Dementia Awareness & 317 & 306 & 11 & 11 & 8.91 & 81 \\
\hline $\begin{array}{l}\text { Dementia Identification, Assessment \& } \\
\text { Diagnosis }\end{array}$ & 201 & 197 & 4 & 19 & 10.84 & 57 \\
\hline Dementia Risk Reduction \& Prevention & 182 & 174 & 8 & 10 & 5.03 & 50 \\
\hline Person-centred Dementia Care & 332 & 289 & 43 & 11 & 7.85 & 71 \\
\hline Communication, Interaction \& Behaviour & 322 & 285 & 37 & 18 & 13.91 & 77 \\
\hline Health \& Wellbeing in Dementia Care & 270 & 238 & 32 & 18 & 10.04 & 56 \\
\hline $\begin{array}{l}\text { Pharmacological Interventions in Dementia } \\
\text { Care }\end{array}$ & 112 & 103 & 9 & 14 & 6.63 & 47 \\
\hline $\begin{array}{l}\text { Living Well with Dementia \& Promoting } \\
\text { Independence }\end{array}$ & 298 & 249 & 49 & 17 & 8.97 & 53 \\
\hline $\begin{array}{l}\text { Families and Carers as Partners in Dementia } \\
\text { Care }\end{array}$ & 267 & 227 & 40 & 18 & 11.19 & 62 \\
\hline Equality Diversity \& Inclusion in Dementia Care & 241 & 197 & 44 & 13 & 6.05 & 47 \\
\hline Law, Ethics \& Safeguarding & 168 & 140 & 28 & 16 & 9.08 & 57 \\
\hline End of Life Dementia Care & 139 & 108 & 31 & 11 & 5.29 & 48 \\
\hline $\begin{array}{l}\text { Research \& Evidence Based Practice in } \\
\text { Dementia Care }\end{array}$ & 176 & 96 & 80 & 9 & 2.09 & 23 \\
\hline Leadership in Transforming Dementia Care & 115 & 109 & 6 & 10 & 6.86 & 89 \\
\hline
\end{tabular}


address over $70 \%$ of the LOs described in The Framework, less than $40 \%$ of the LOs were covered at Tier 2 and Tier 3.

\section{Discussion}

The findings of this audit highlight the variability in the degree and nature of education and training in dementia care across the UK. The national dementia strategy in the UK has been in place for 14 years; but only relatively recently (2015) has a national standard of dementia of education and training been described. Internationally, countries have adopted a variety of approaches to improve the quality of life of people with dementia; some have launched policies, others plans, strategies or frameworks [1]. There is considerable variability with regards to how much these plans reflect a need to improve dementia related education and training. These audit findings will have relevance for countries wishing to improve or develop education and training. For countries seeking to develop standards of education and training the findings suggest avoiding a one fits all approach; ensuring that a breadth of training at all levels is available to staff. For example in Malaysia where a dementia strategy has only recently been adopted which is predicated in the UK model [18].

The responses in the current audit were obtained from a range of health and social care settings in the UK. Many respondents came from hospital settings and care homes providers, where dementia care is prioritised as many service users live with dementia [4], and there are significant costs associated with inadequate care [3]. There were high numbers of respondents from University organisations which reflected a range of approaches to programme delivery ranging from dedicated dementia specific programmes (e.g. postgraduate dementia courses) to dementia training that is integrated with professional training (e.g. dementia specific mentorship on placement). This may reflect an increased awareness of the importance of dementia in interprofessional training [19]. In contrast, lower numbers of responses from primary care may be because these organisations are generally small-scale and professional training is often organised on an individual basis rather than by the provider, who may not be aware of the extent and nature of training staff have received.

The audit considered the pedagogy of the education and training provided; an important consideration given that there is established universal evidence base regarding good pedagogical practice. For example, it is well established that assessment is an important component of learning [20]. Only 35\% of packages indicated that they used assessment. One of the limitations of the current study was that we did not ask participants whether learning outcomes had been defined at the outset of the training. From a pedagogical perspective establishing learning outcomes at the outset of training is critical to ensure that the educator and learner have a clear understanding of the purpose of the training [21] and therefore what is being assessed as an outcome. The inclusion of clear learning outcomes as well as assessment in dementia education and training should be considered; accreditation for dementia specialist staff may incentivise this practice.

The audit highlighted that training was performing well in terms of the methods of delivery; the majority of the packages used face to face approaches to teaching. This is in line with previous research in the field suggesting this method achieves high impact [16], with the caveat that impactful face to face training should also provide opportunities for interaction. Fewer of the reported packages used e-learning, a positive finding given the literature indicates that this is a less effective form of teaching [16] and the recent National Audit of Dementia

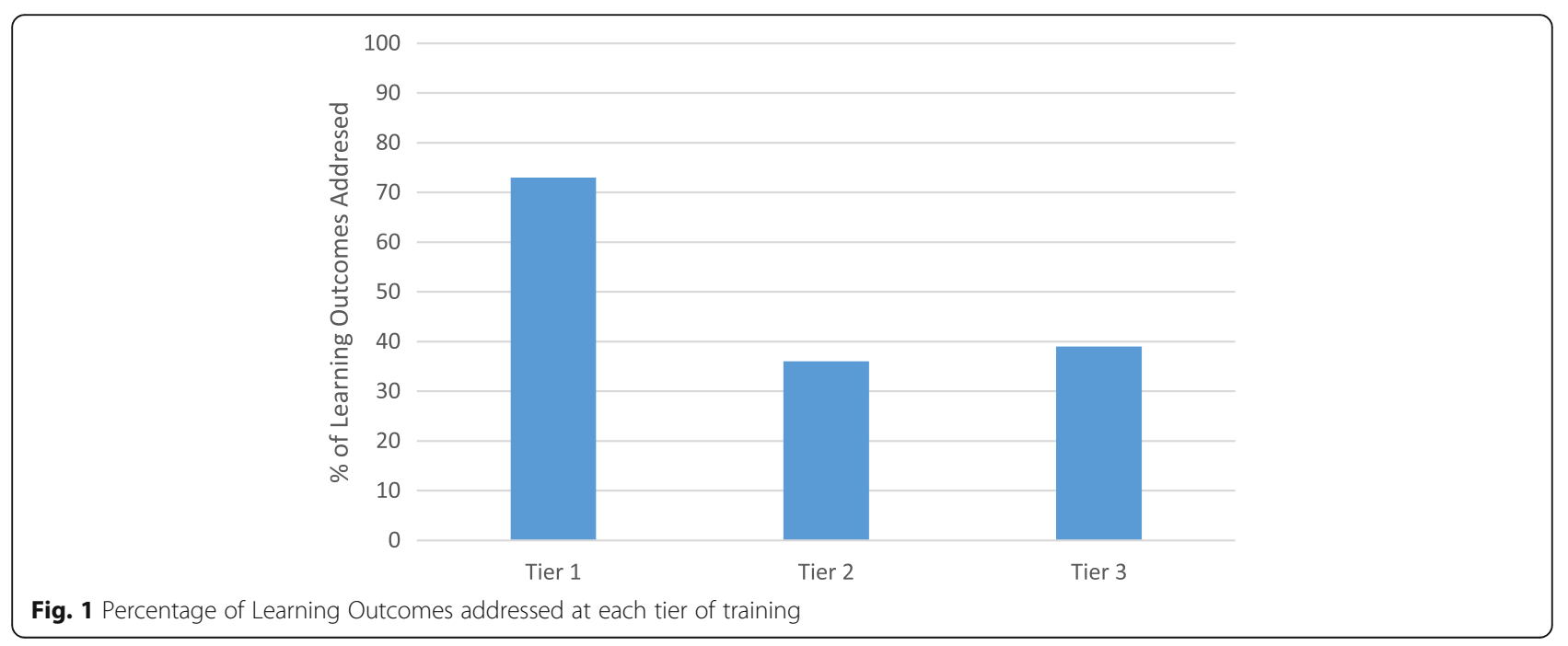


conducted in hospitals by the Royal College of Psychiatrists in England and Wales found that staff who had only received e learning training felt the least prepared to care for people with dementia [22].

The current audit found that there was a good coverage of education and training provided at Tier 1; the topic if 'dementia awareness' was addressed by many of the packages and corresponded well to the LOs described in The Framework. This is likely to reflect the commitment from DoH in England that all health and social care staff should be dementia aware by 2015 [7]. However, ancillary staff such as porters and staff provided by external companies may still be overlooked, the current findings reported that few packages were targeted to these staff groups. This corresponds with findings from the 2019 National Audit of Dementia [22] which identified that the requirement for staff to have dementia training was detailed in fewer than $40 \%$ of contracts with external providers.

In terms of the content of the training provided in the packages reported in the current audit, whilst Tier 1 was covered comprehensively, there was greater variation in the degree to which Tier 2 and tier 3 learning outcomes were met. Overall, fewer than $40 \%$ of learning outcomes overall were addressed in the packages reported. The subjects 'communication, interaction $\mathcal{E}$ behaviour' and 'person-centred care' were addressed thoroughly in terms of the learning outcomes that were covered by training packages, and were also the subjects most frequently targeted in training packages. As a finding this was unsurprising given the policy driven approach to provision of person-centred care that has grown since the inception of the concept of personhood in the field [23]. Additionally, person-centred care and communication are pertinent to all professional roles and services, whereas other subject areas may be considered specialist or role specific. Countries such as Ireland [24] and the Netherlands [25] have also adopted person-centred stances on dementia care in the past 10 years, embedding this into their national dementia strategies. In countries that have adopted similar approaches to person centred care, we may anticipate similar issues with education and training may arise i.e. a greater degree of generalised training in person centred care rather than specialist role specific training.

Only $23 \%$ of the LOs for 'research \& evidence based practice' were addressed, poorer coverage may reflect a lack of understanding regarding contemporary issues and practice. Given that current UK based policy from the National Institute for Health and Care Excellence requires everyone who is diagnosed with dementia to be offered research participation and emphasises evidence-based services, new or updated training in this domain is recommended. The subjects 'pharmacological interventions in dementia care' and 'end of life dementia care' were less likely to be the targeted by training. These subjects may have a more limited audience; specialist rather than generic dementia roles. In and of itself this is not problematic, but there were also fewer LOs covered in these subjects suggesting that the training currently offered does not reflect that recommended standards identified in the Framework. This is particularly important given controversial issues that can arise in fields such as prescribing, for example the overuse of antipsychotics in dementia care [26]. Fewer LOs covered in the subject 'equality diversity $\mathcal{E}$ inclusion' suggest the same issue. Training in these subject areas may benefit from being further developed or updated.

The reach of the packages was interrogated by investigating how many learners had undertaken the training and the number of times the training had been delivered. Although prima facie it is good to see training reaching large numbers of learners, where this occurred in many cases the training had been delivered multiple times. Training that is delivered multiple times may also be predisposed to be shorter and this suggestion is perhaps corroborated by the finding that most of the packages did not exceed the eighthour duration found in our related literature review to be the threshold for training to impact knowledge and behaviour [16]. In developing new and updating existing training packages these issues should be considered; as it is important not to prioritise accessibility over quality and impact.

At the time of this audit the original Framework had only just been released and therefore training providers could not have planned their training to deliver against its learning outcomes. This may explain the large number who started but did not complete the survey. A further limitation is that we cannot be certain whether the responses reflect the full extent of dementia training and education in England as it is possible that many organisations who deliver training did not complete the survey. However, we made every attempt to bring this to relevant audiences through a variety of media to give all an opportunity to respond, and we were able to analyse reports on 386 training packages, which is a substantial number. Future research may consider repeating the audit to consider whether education and training now reflects The Framework to a greater degree.

\section{Conclusion}

As argued by Surr et al. [16], adapted from Opfer \& Pedder [27], the health and social care workforce education is a complex system, with many facets at individual, meso, and macro (institutional) levels that must be understood to provide effective conditions for learning. However, in reviewing the current education and training offered in the UK in relation to best practice 
evidence, it is apparent that immediate changes to the content of training can be implemented that will better equip the dementia workforce to deliver high quality person-centred care. In particular although dementia awareness training is covered effectively, fewer than $40 \%$ of The Dementia Training Standards Framework learning outcomes targeted to staff with regular contact with people with dementia or in leadership roles were covered by the reported packages. Training targeting the subjects 'pharmacological interventions in dementia care', 'leadership' and 'end of life care' should be enhanced. Although many of the reported packages used delivery methods considered to be effective, on the while the training was not of sufficient duration to derive impact.

In the UK, findings from this audit have been used to inform quality improvement initiatives, such as the guidance document Managing Success which accompanies The Dementia Training Standards Framework [28]. These findings are also relevant to countries outside of the UK in the short and long term who may be seeking to review or develop their national training.

\section{Supplementary information}

The online version of this article (https://doi.org/10.1186/s12913-019-4510-6) contains supplementary material, which is available to authorized users.

Additional file 1: Sample of Audit.

\begin{abstract}
Abbreviations
CPD: Continuing Professional Development; DoH: Department of Health; HEE: Health Education England (HEE); LO: Learning Outcome; NHS: National Health Service; NICE: National Institute for Health and Care Excellence; NVQ: National Vocational Qualification; R\&D: Research and Development (R\&D); UK: United Kingdom
\end{abstract}

\section{Acknowledgements}

Not applicable.

\section{Authors' contributions}

All authors meet the criteria for authorship stated in the Uniform Requirements for Manuscripts Submitted to Biomedical Journals. SS contributed to the conception \& design of the audit, acquisition of data, analysis and interpretation of data, drafting of the article and revisions for critical content and final approval of the article. SP contributed to the conception \& design of the audit, interpretation of data, revisions for critical content and final approval of the article. CS [1] contributed to the conception \& design of the audit, acquisition of data, revisions for critical content and final approval. MD contributed to the acquisition of data, revisions for critical content and final approval. JO contributed to the conception \& design of the audit, acquisition of data, revisions for critical content and final approval. CAS [2] contributed to the conception \& design of the audit, acquisition of data, revisions for critical content and final approval.

\section{Funding}

The report is based on independent research commissioned and funded by the NIHR Policy Research Programme (Understanding Effective Dementia Workforce Education and Training: A Formative Evaluation (DeWET Evaluation), PR-R10-0514-12006). The funding body had no role in the design of the study and collection, analysis, and interpretation of data and in writing the manuscript. The views expressed in the publication are those of the author(s) and not necessarily those of the NHS, the NIHR, the Department of Health and Social care, 'arms' length bodies or other government departments.

\section{Availability of data and materials}

The datasets used and/or analysed during the current study are available from the corresponding author on reasonable request.

\section{Ethics approval and consent to participate}

Ethical approval was obtained from Leeds Beckett University Research Ethics Committee.

Written consent to take part in the survey was explicitly obtained at the start of the survey, information regarding withdrawal and data protection was provided in an information sheet presented before commencing the survey (see Additional file 1 for copy of audit including information sheet and consent).

Consent for publication

Not applicable.

\section{Competing interests}

The authors declare that they have no competing interests.

\section{Author details}

${ }^{1}$ Centre for Dementia Research, School of Health and Community Studies, Leeds Beckett University, Leeds LS1 3HE, UK. ${ }^{2}$ Centre for Applied Dementia Studies, Faculty of Health Studies, University of Bradford, Bradford BD5 OBB, UK.

Received: 15 April 2019 Accepted: 3 September 2019

Published online: 21 October 2019

\section{References}

1. Alzheimer's Disease International. Dementia: A Public Health Priority London: WHO; 2012. https://www.who.int/mental_health/publications/ dementia_report_2012/en/.

2. Alzheimer's Disease International. World Alzheimer Report. The state of the art dementia research; New frontiers. London, 2018. https://www.alz.co.uk/ news/world-alzheimer-report-2018-state-of-art-of-dementia-research-newfrontiers. Accessed 15 July 2019.

3. Alzheimer's Society. Counting the cost. Caring for people with dementia on hospital wards. London: Alzheimer's Society; 2009. https://www.alzheimers. org.uk/sites/default/files/2018-05/Counting_the_cost_report.pdf. Accessed 15 July 2015.

4. Prince M, Knapp M, Guerchet M, McCrone P, Prina M, Comas-Herrera A, et al. Dementia UK: report to the Alzheimer's society. London: Alzheimer's Society; 2014. https://www.alzheimers.org.uk/sites/default/files/migrate/ downloads/dementia_uk_update.pdf. Accessed 15 July 2019.

5. Revolta C, Orrell M. Spector A The Biopsychosocial (BPS) model of dementia as a tool for clinical practice. A pilot study. Int Psychogeriatr. 2016;28(7): 1079-89. https://doi.org/10.1017/S1041610215002379.

6. Manthorpe J, Samsi K. Person-centered dementia care: current perspectives. Clin Interv Aging. 2016;11:1733-40. https://doi.org/10.2147/CIA.S104618.

7. Department of Health. Delivering high quality, effective, compassionate care: Developing the right people with the right skills and the right values: A mandate from the Government to Health Education England: April 2016 to March 2017. London; 2016. https://www.bl.uk/collection-items/deliveringhigh-quality-effective-compassionate-care-developing-the-right-people-withthe-right-skills-and-the-right-values-a-mandate-from-the-government-tohealth-education-england-april-2016-to-march-2017. Accessed 15 July 2019.

8. Finnema E, Dröes RM, Ettema T, Ooms M, Adèr H, Ribbe M, van Tilburg W. The effect of integrated emotion-oriented care versus usual care on elderly persons with dementia in the nursing home and on nursing assistants: a randomized clinical trial. Int J Geriatr Psychiatry. 2005;20:330-43.

9. Royal College of Psychiatrists. Report of the national audit of dementia care in general hospitals. London: Healthcare Quality Improvement Partnership; 2011. https://dementiapartnerships.com/national-audit-of-dementia-care-ingeneral-hospitals-2011/. Accessed 15 July 2019.

10. Department of Health. Delivering high quality, effective, compassionate care: Developing the right people with the right skills and the right values: A mandate from the Government to Health Education England: April 2013 to March 2015. London; 2013. https://assets.publishing.service.gov.uk/ government/uploads/system/uploads/attachment_data/file/203332/29257_2 900971_Delivering_Accessible.pdf. Accessed 15 July 2019. 
11. Department of Health. Delivering high quality, effective, compassionate care: developing the right people with the right skills and the right values: a mandate from the government to health education England: April 2014 to march 2015.London: Author (Health Education England Skills for Health and Skills for Care, 2015), 2015. https://assets.publishing.service.gov.uk/ government/uploads/system/uploads/attachment_data/file/310170/DH_ HEE_Mandate.pdf. Accessed 15 July 2019.

12. Skills for Health, Health Education England, Skills for Care. Dementia Core Skills Education and Training Framework Skills for Health, London; 2015. https://www.housinglin.org.uk/_assets/Resources/Housing/ OtherOrganisation/Dementia_Core_Skills_Education_and_Training_ Framework.pdf. Accessed 15 July 2019.

13. Skills for Health, Health education England, skills for care. Dementia training standards framework. London: Skills for Health; 2018. https:/www.housinglin. org.uk/_assets/Resources/Housing/OtherOrganisation/Dementia-Core-SkillsEducation-and-Training-Framework-July-2018.pdf. Accessed 15 July 2019.

14. All-Party Parliamentary Group on Dementia. Prepared to care: Challenging the dementia skills gap. London: Stationary Office; 2009. https:/www. alzheimers.org.uk/sites/default/files/migrate/downloads/appg_report_ prepared_to_care.pdf. Accessed 15 July 2019.

15. Wilson JH. Investing in English skills: The limited English proficient workforce in U.S. metropolitan areas. Washington, DC: Metropolitan Policy Programme at Brookings; 2014. https://www.brookings.edu/wp-content/uploads/2014/09/ metro_20140924 investing_in_english_skils_report.pdf. Accessed 15 July 2019.

16. Surr C, Gates C, Irving D, Oyebode J, Smith SJ, Parveen S, et al. Effective dementia education and training for the health and social care workforce: a systematic review of the literature. Rev Educ Res. 2015;87(5):966-1002.

17. Kirkpatrick DL. Evaluating training programs: The four levels. San Francisco: Berrett-Koehler; 1984.

18. $\mathrm{MOH}$ Malaysia. Clinical practice guideline: Management of Dementia, $2^{\text {nd }}$ Ed. Ministry of Health Malaysia, 2009. http://www.moh.gov.my/moh/ attachments/4484.pdf. Accessed 15 July 2019.

19. Banerjee S, Farina N, Daley S, Grosvenor W, Hughes L, Hebditch M, Mackrell S, Niforooshan R, Wyatt C, de Vries K, Haq I, Wright J. How do we enhance undergraduate healthcare education in dementia? A review of the role of innovative approaches and development of the time for dementia programme. Int J Geriatr Psychiatry. 2017;32:68-75.

20. Biggs J, Tang K. Teaching for quality learning at university. 4th ed. Maidenhead: Oxford University Press; 2011.

21. Anderson LW, Krathwohl DR. \& bloom BSA. Taxonomy for learning, teaching, and assessing: a revision of Bloom's taxonomy of educational objectives: Allyn \& Bacon; 2001.

22. Royal College of Psychiatrists, National Audit of Dementia Forth Round of Audit Report, London; 2019. https://www.rcpsych.ac.uk/docs/default-source/ improving-care/ccqi/national-clinical-audits/national-audit-of-dementia/ national-audit-of-dementia-round-4-report-online-v2.pdf?sfvrsn=28e025 c5_2\%20. Accessed 12 Aug 2019.

23. Kitwood T. Dementia reconsidered: The person comes first. Berkshire: Open University Press; 1997.

24. Minister for Health. The Irish national Dementia Strategy. Department of Health, Ireland, 2014. https://health.gov.ie/wp-content/uploads/2014/12/3 0115-National-Dementia-Strategy-Eng.pdf. Accessed 15 July 2019.

25. State Secretary for Health, Welfare and Sports. Dutch Dementia Strategy Ministry of Welfare and Sports. Netherlands, 2008. https://www.alzheimereurope.org/Policy-in-Practice2/National-Dementia-Strategies/Netherlands. Accessed 15 July 2019

26. Banerjee $\mathrm{S}$. The use of antipsychotic medication for people with dementia: time for action. A report for the minister of state for care services London: Department of Health, 2009. https://www.jcpmh.info/wp-content/uploads/ time-for-action.pdf. Accessed 12 August 2019.

27. Opfer VD, Pedder D. Conceptualizing teacher professional education. Rev Educ Res. 2011;81(3):376-407. https://doi.org/10.3102/0034654311413609.

28. Skills for Health, Skills for Care, Leeds Beckett University and Health Education England. Managing success in dementia care. 2018. https://www. hee.nhs.uk/sites/default/files/documents/Managing\%20Success\%20v3.pdf. Accessed July 2019.

\section{Publisher's Note}

Springer Nature remains neutral with regard to jurisdictional claims in published maps and institutional affiliations.

Ready to submit your research? Choose BMC and benefit from:

- fast, convenient online submission

- thorough peer review by experienced researchers in your field

- rapid publication on acceptance

- support for research data, including large and complex data types

- gold Open Access which fosters wider collaboration and increased citations

- maximum visibility for your research: over $100 \mathrm{M}$ website views per year

At $\mathrm{BMC}$, research is always in progress.

Learn more biomedcentral.com/submissions 